\title{
Gambaran Status, Derajat dan Profil Merokok serta Ketergantungan Nikotin pada Pasien Perokok yang Dirawat di Bangsal Paru RSUP DR. M.
}

\section{Djamil Padang}

\author{
Suyastri $^{1}$, Sabrina Ermayanti ${ }^{2}$, Russilawati ${ }^{3}$ \\ Fakultas Kedokteran Universitas Andalas \\ Email :suyastri31@gmail.com
}

Submitted: 21-12-2019, Reviewer: 26-12-2019, Accepted: 30-12-2019

\begin{abstract}
Abstrak
Merokok masih merupakan masalah kesehatan utama yang menyebabkan 7,1 juta kematian setiap tahun. Prevalensi merokok di Indonesia adalah yang kelima di dunia. Berdasarkan Riskesdas pada 2007 dan 2010 menunjukkan peningkatan jumlah perokok dari 29\% - 34,7\%. Metode: Ini adalah studi deskriptif prospektif pada 177 pasien yang dirawat di bangsal paru Dr. M. Djamil Padang dari November 2016 hingga 31 Januari 2017. Data dikumpulkan melalui wawancara pasien dengan pertanyaan tertutup dan kuesioner yang divalidasi. Hasil: Studi ini menemukan total 177 pasien yang terdiri dari $128(72,4 \%)$ laki-laki dengan usia rata-rata 52,5 \pm 15,57 tahun SD. Riwayat merokok adalah 63 perokok (35,6\%), 67 bukan perokok (37,8\%) dan mantan perokok 47 (26,5\%). Pasien perokok ditemukan paling banyak adalah pasien dengan karsinoma bronkogenik 24 (38\%), dengan profil untuk stres $34(54 \%)$, dan indeks Brinkman berat. Mantan perokok kebanyakan pada pasien dengan pneumonia $11(23,4 \%)$ dan COPD $10(21,2 \%)$. Ketergantungan nikotin rendah sampai sedang $13(56,5 \%)$ pada pasien dengan karsinoma bronkogenik dan ketergantungan rendah 10 (53\%) pada pasien TB. Kesimpulan: Pasien yang dirawat di bangsal paru lebih dari sepertiga adalah perokok. Profil yang paling umum adalah untuk kesenangan dan ketergantungan nikotin adalah rendah hingga sedang sehingga memberikan kesempatan kepada kita untuk melakukan intervensi pendidikan.

Kata kunci: riwayat merokok, profil merokok, ketergantungan nikotin
\end{abstract}

\begin{abstract}
Smoking was still health major problem in the word that lead 7.1 million smoking related deaths annually. Prevalence smoking in Indonesia was fifth in the world. Based on Riskesdas in 2007 and 2010 showed an increase number of smokers from 29\% - 34.7\%. Methods: This is Descriptiveprospective study in 177 patients who were treated in pulmonary ward of Dr. M. Djamil Padang from November 2016 to January 31, 2017. Data were collected through interviews patients with closed questions and validated questioner. Results: This study found total 177 patients that consist of 128 $(72.4 \%)$ males with an average age of $52.5 \pm 15.57$ SD years. History of smoking were 63 smokers (35.6\%), 67 nonsmokers (37.8\%) and former smokers 47 (26.5\%). Smoker patients have been found most in bronchogenic carcinoma patients 24 (38\%), with profile for stress 34 (54\%), and the Brinkman index grade was severe. Former smokers were mostly in patients with pneumonia 11 (23.4\%) and COPD 10 (21.2\%). The nicotine dependence is low to moderate 13 (56.5\%) in patients with bronchogenic carcinoma and low dependence 10 (53\%) in TB patients. Conclusion: Patients that were treated in the pulmonary ward more than third were smokers. The most common profile was for pleasure and nicotine dependence mostly low to moderate could give opportunity for educational intervention.
\end{abstract}

Keyword: history of smoking, profile of smoking, nicotine dependence 


\section{PENDAHULUAN}

Merokok merupakan masalah yang kompleks tidak saja berhubungan dengan aspek kesehatan, namun juga aspek ekonomi, sosial, budaya bahkan masalah keagamaan. ${ }^{1}$ Data WHO tahun 2008 menunjukkan terdapat 1,25 milyar perokok dewasa dengan usia diatas 15 tahun di seluruh dunia dengan prevalensi sebesar 24\%. Prevalensi perokok ini dari tahun ke tahun mengalami peningkatan pada negara berkembang yaitu $2,1 \%$ tiap tahunnya, sedangkan pada negara maju mengalami penurunan. $^{2}$

Menurut the Tobacco Atlas $3^{\text {rd }}$ edition tahun 2009 terkait presentase penduduk dunia yang mengkonsumsi tembakau didapatkan sebanyak $57 \%$ pada penduduk Asia dan Australia, 14\% pada penduduk Timur Tengah dan Afrika. ${ }^{3}$ Prevalensi perokok di ASEAN 10\% dari seluruh perokok dunia. Perokok Indonesia terus meningkat dari tahun 2000 sampai 2013 yaitu dari $36 \%$ menjadi $38 \%$. Indonesia menduduki urutan kedua jumlah perokok di dunia setelah India dan urutan pertama di ASEAN. ${ }^{4}$ Sebanyak 17 provinsi di Indonesia mempunyai prevalensi merokok setiap hari di atas prevalensi nasional (24,3\%). Prevalensi perokok di Sumatera Barat $(25,7 \%)$ menduduki urutan keenam setelah Bengkulu, Lampung, Gorontalo, Jawa Barat dan Banten. 5,6

Rokok merupakan penyebab kematian nomor satu. Merokok membunuh hampir 6 juta orang tiap tahunnya, 5 juta dari perokok dan sisanya dari paparan asap rokok. Pada tahun 2010, diperkirakan 384.058 orang di Indonesia menderita penyakit terkait konsumsi tembakau. Total kematiannya akibat konsumsi rokok mencapai $12,7 \%$ dari total kematian pada tahun 2010. Penyebab utama kematian yang berhubungan dengan rokok adalah kanker, penyakit kardiovaskuler, dan penyakit paru seperti bronkhitis, emfisema/PPOK dan pneumonia. $^{2,3}$

Melihat tinggi kematian akibat rokok dan hubungannya dengan penyakit paru terutama kanker paru dan PPOK, maka berhenti merokok sebagai usaha pencegahan primer maupun sekunder sudah seharusnya dapat kita laksanakan di setiap pelayanan kesehatan paru dan layanan primer. Untuk menunjang usaha berhenti merokok, perlu diketahui status, derajat dan profil merokok serta ketergantungan nikotin pada pasien perokok berdasarkan penyakit yang berhubungan dengan rokok. Dalam rangka usaha ini peneliti merasa perlu untuk membuat laporan tentang status, derajat dan profil merokok serta ketergantungan nikotin pada pasien perokok yang di rawat di bangsal paru RSUP.DR..M.Djamil Padang..

\section{METODE}

Penelitian ini adalah penelitian deskriptif prospektif dan data diambil dari hasil wawancara dengan pasien yang dirawat di bangsal paru RSUP DR.M.Djamil Padang pada periode 01 November 2016 sampai Januari 2017. Sampel diambil dari semua populasi yang memenuhi kriteria inklusi dan ekslusi. Kriteria inklusi sebagai berikut semua pasien perokok yang dirawat di bangsal paru RSUP DR. M.Djamil Padang yang kooperatif dan bisa menjawab semua petanyan pada lembar pertanyaan yang diberikan pada periode mulai 01 November 2016 sampai 31 Januari 2017, dan penderita yang dirawat lebih dari satu kali dengan diagnosa yang sama dicatat hanya satu kali saat penderita di rawat untuk pertama kalinya. Kriteria ekslusinya adalah pasien yang telah dirawat sebelum tanggal 01 November 2016.

Data yang dikumpulkan meliputi umur, jenis kelamin, pekerjaan, riwayat merokok, status merokok, derajat merokok, profil merokok dan ketergantungan nikotin serta diagnosis sampel (tuberkulosa, $\mathrm{PPOK}<$ $\mathrm{Ca}$ bronkogenik, asma, pneumonia, bronkiektasis, dan lain-lain. Data yang diperoleh diolah secara manual dan disajikan dalam bentuk tabel distribusi frekuensi dan grafik. Data kontinu yang terdistribusi secara normal disajikan berupa mean (rata-rata), dan data kelompok 
disajikan dalam bentuk frekuensi dan persentase.

\section{HASIL DAN PEMBAHASAN (70\%)}

\section{Hasil Penelitian}

Dari 177 pasien yang dirawat dibangsal paru RSUP DR. M.Djamil Padang dengan umur rata-rata $47,5 \%$ dengan jenis kelamin laki-laki $72,4 \%$ terdiri dari bukan perokok $67(37,8 \%)$, perokok $63(35,6 \%)$ dan bekas perokok 47 (26,5\%). Data karakteristik umum pasien dirawat terlihat pada tabel di bawah ini:

Tabel 1. Data karakteristik umum pasien yang dirawat

\begin{tabular}{|c|c|c|c|c|}
\hline $\begin{array}{l}\mathrm{N} \\
\mathrm{O}\end{array}$ & $\begin{array}{l}\text { Karakteristik } \\
\text { umum }\end{array}$ & $\mathrm{N}$ & $f(\%)$ & \multirow{15}{*}{$\begin{array}{l}\text { Dari } 177 \text { populasi tersebut sampel yang } \\
\text { memenuhi kriteria inklusi adalah } 63 \text { sampe } \\
(35,6 \%) \text { pasien perokok dengan diagnose } \\
\text { terbanyak adalah karsinoma bronkogenik } \\
38 \% \text { dengan umur rata-rata } 50,5 \text { tahun dar } \\
\text { pekerjaan terbanyak adalah petani. Penyaki } \\
\text { tuberkulosa pada penelitian ini berada pada } \\
\text { penyakit } 2 \text { terbanyak yaitu } 28,6 \% \text { dengan } \\
\text { umur rata-rata } 44 \text { tahun dengan pekerjaan } \\
\text { buruh dan wiraswasta. Dan pada penelitian } \\
\text { ini tidak didapatkan diagnosa bronkiektasi } \\
\text { dan diagnosa paling sedikit adalah asma } \\
1,6 \% \text {. Karakteristik sampel dapt dilihat pada } \\
\text { tabel } 2 \text { dibawah ini: }\end{array}$} \\
\hline 1 & Umur rata-rata & $52.5 \pm 15.57 \mathrm{SD}$ & & \\
\hline \multirow[t]{13}{*}{2} & $\begin{array}{l}\text { Jenis kelamin } \\
\text { Pekerjaan }\end{array}$ & $\hat{\delta}=128$ & 72,4 & \\
\hline & a. Petani & 39 & 22 & \\
\hline & b. Pedagang & 20 & 11,3 & \\
\hline & c. Sopir & 8 & 4,5 & \\
\hline & d. Buruh & 12 & 6,8 & \\
\hline & Angkat & 3 & 1,7 & \\
\hline & e. Nelayan & 23 & 13,1 & \\
\hline & f. Wiraswast & 19 & 10,7 & \\
\hline & $\mathrm{a}$ & 5 & 2,8 & \\
\hline & g. Pensiunan & 15 & 8,5 & \\
\hline & h. Pelajar & 33 & 18,6 & \\
\hline & i. PNS & & & \\
\hline & $\begin{array}{l}\text { j. Dan lain } \\
\text { lain }\end{array}$ & & & \\
\hline
\end{tabular}

4 Jenis penyakit

$\begin{array}{lll}\text { a. Ca } & 49 & 27,6 \\ \text { bronkogenik } & 38 & 21,4 \\ \text { b. Pneumoni } & 20 & 11,3 \\ \text { a } & 9 & 5\end{array}$

Tabel 2: karakteristik sampel

\begin{tabular}{|l|l|l|l|l|l|l|l|}
\hline Karakteristik & $\begin{array}{l}\text { Ca } \\
\text { bronkogen } \\
\text { ik }\end{array}$ & $\begin{array}{l}\text { Pneumon } \\
\text { ia }\end{array}$ & $\begin{array}{l}\text { PPO } \\
\text { K }\end{array}$ & $\begin{array}{l}\text { Asm } \\
\text { a }\end{array}$ & $\begin{array}{l}\text { Tuberculo } \\
\text { sis }\end{array}$ & $\begin{array}{l}\text { bronkiekta } \\
\text { sis }\end{array}$ & $\begin{array}{l}\text { Dan } \\
\text { lain- } \\
\text { lain }\end{array}$ \\
\hline Umur & 50,5 & 54 & 64,5 & 45 & 44 & 0 & 46 \\
\hline $\begin{array}{l}\text { Jenis kelamin } \hat{\jmath} \\
24(38)\end{array}$ & $10(16)$ & $\begin{array}{l}8(12, \\
7)\end{array}$ & $\begin{array}{l}1(1,6 \\
)\end{array}$ & $18(28,6)$ & 0 & $\begin{array}{l}2(3, \\
2)\end{array}$ \\
\hline $\begin{array}{c}\text { Pekerjaan: } \\
\text { a. Petani }\end{array}$ & $9(38)$ & $3(30)$ & $5(63)$ & 0 & $1(56)$ & 0 & 0 \\
\hline
\end{tabular}




\begin{tabular}{|l|l|l|l|l|l|l|l|}
\hline b. Pedagang & $4(17)$ & $1(10)$ & 0 & 0 & $2(11)$ & 0 & 0 \\
c. Nelayan & $2(8)$ & $1(10)$ & 0 & 0 & 0 & 0 & 0 \\
d. PNS \& & $1(4)$ & $1(10)$ & $1(12)$ & 0 & $1(55)$ & 0 & 0 \\
guru & 0 & $1(10)$ & 0 & 0 & $4(22)$ & 0 & 0 \\
e. Buruh & $5(21)$ & 0 & $2(25)$ & 0 & $4(22)$ & 0 & 0 \\
f. Wiraswasta & $1(4)$ & $1(10)$ & 0 & 0 & $1(56)$ & 0 & $1(50$ \\
g. Pensiun0an & 0 & 0 & 0 & 0 & $2(11)$ & 0 & ) \\
h. Pelajar dan & $2(8)$ & $2(20)$ & 0 & $1(10$ & $3(17)$ & 0 & 0 \\
mahasiswa & & & & $0)$ & & & \\
i. Dan lain- & & & & & & & \\
\hline \\
\hline
\end{tabular}

Derajat merokok pada pasien perokok penelitian ini terdiri dari derajat merokok ringan, sedang dan berat. Pada penelitian ini derajat merokok paling banyak yaitu derajat merokok sedang yang ditemukan pada penderita tuberkulosis $60 \%$ dan diikuti derajat merokok ringan 55\%. Pada diagnosa terbanyak pada penelitian ini karsinoma bronkogenik derajat merokoknya paling banyak derajat merokok berat $43 \%$ dan diikuti dengan derajat merokok sedang $40 \%$. Derajat merokok ringan banyak ditemukan pada penderita tuberculosis $5 \%$ dan pneumonia 22\%. Gambaran distribusi derajat merokok dapat dilihat pada grafik 4.1 di bawah ini:

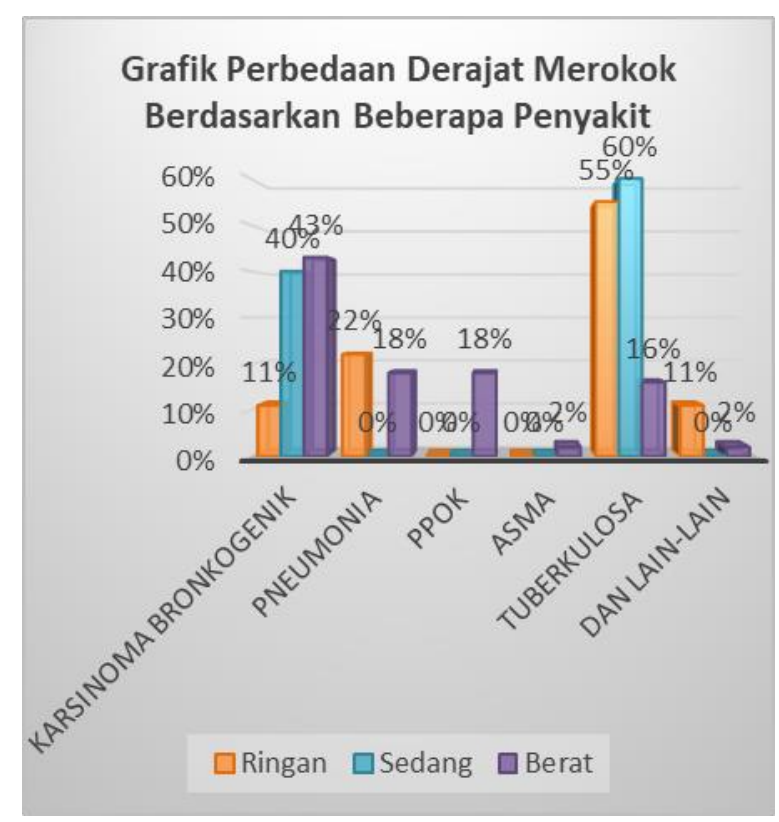

Gambar 1. Grafik perbedaan derajat merokok berdasarkan beberapa penyakit

Profil perokok pada pasien yang dirawat terdiri dari stimulasi, kesenangan, kecanduan, pegangan, kebiasaan, stress dan sosial. Dari hasil penelitian profil perokok pada pasien berdasrkan komorbid paling tinggi adalah asma $100 \%$ pada stimulasi. kesenangan. kecanduan, kebiasaan strees dan sosial karena pasien yang didiagnosa asma adalah 1 orang dan tidak dapat diambil kesimpulan. Secara umum profil perokok pada penelitian ini adalah strees dan sosial pada kelompok penyakit komorbid karsinoma bronkogeni, tuberkulosa dan PPOK. Profil perokok palng rendah yaitu kecanduan dan pegangan yaitu pada kelompok penyakit PPOK dan pneumonia. Gambaran profil merokok berdasarkan penyakit dapat dilihat pada grafik di bawah ini:

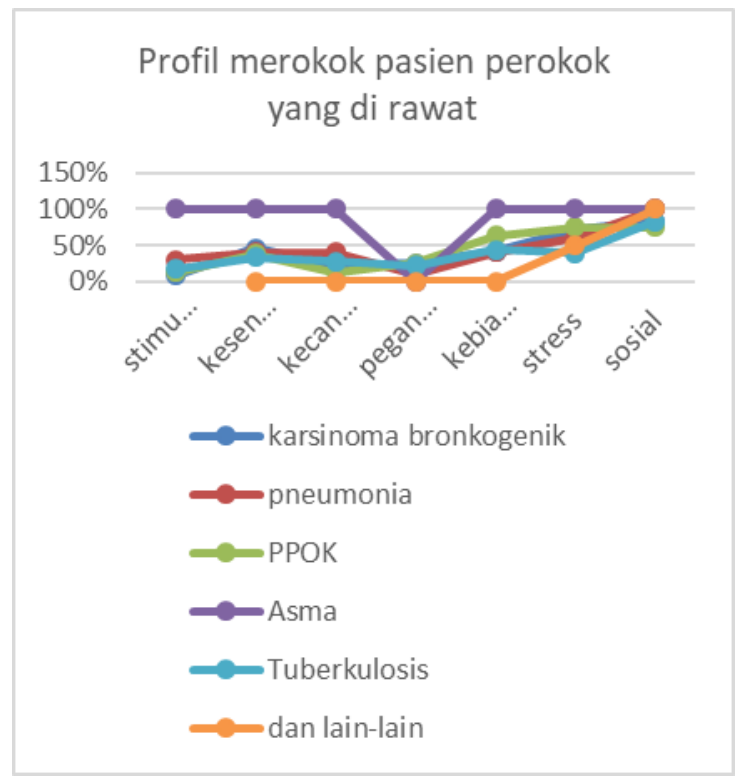


Gambar 2. Grafik profil merokok pasien perokok yang dirawat di bangsal paru RSUP DR.M.Djamil Padang

Derajat ketergantungan nikotin pasien perokok terdiri dari derajat ringan, ringansedang, sedang dan berat. Pada penelitian ini didapatkan derajat merokok pasien perokok yang di rawat di bangsal paru RSUP DR.M.Djamil Padang paling banyak adalah derajt ketergantungan nikotin rendah-sedang $36,5 \%$ pada penyakit komorbid karsinoma bronkogenik dan tuberculosis. Sedangkan derajat ketergantungan sedang berapada pada diagnosis karsinoma bronkogenik $56,5 \%$ dan derajat ketergantungan ringan tuberculosis $53 \%$ dan karsinoma bronkogenik 21\%. Gambaran derajat ketergantungan nikotin dapat dilihat pada grafik dibawah ini

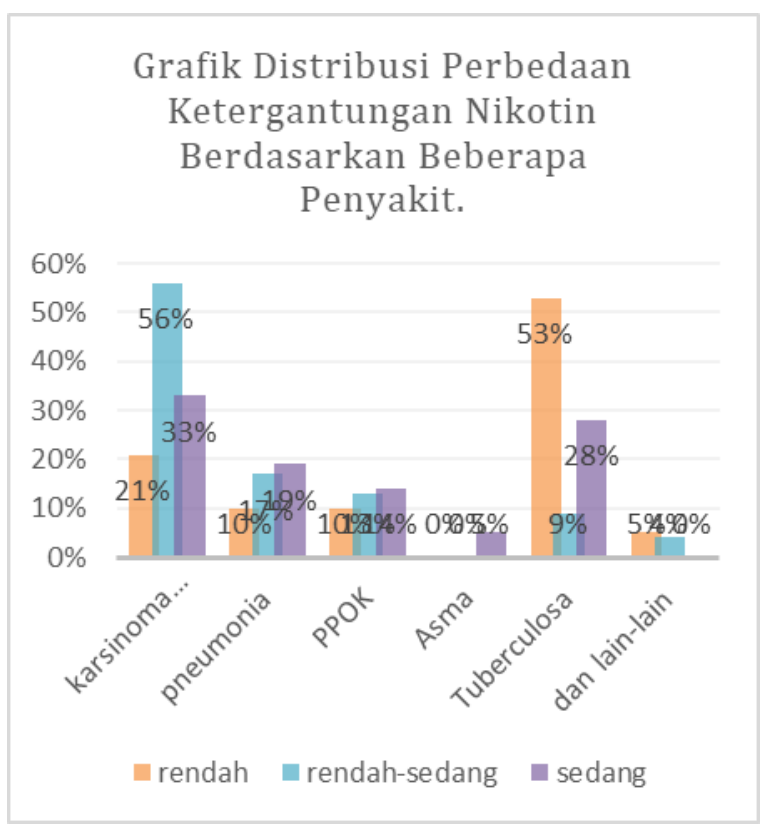

\section{Pembahasan}

Merokok merupakan masalah terbesar di dunia dengan prevalensi yang cukup tinggi dan berhubungan dengan resiko penyakit dan tingginya angka kematian. Di Indonesia prevalensi merokok terus meningkat, laki-laki lebih banyak dari perempuan $26,4 \%$. Pada penelitian ini prevalensi merokok terbanyak adalah lakilaki $49 \%$ dari semua pasien laki-laki yang dirawat. $^{2}$

Dari beberapa laporan penyakit paru dan respirasi yang berhubungan dengan merokok diantaranya adalah PPOK, kanker paru, TB paru, pneumonia dan asma. ${ }^{7}$ Penelitian Youldan dkk dalam melaporkan resiko karsinoma bronkogenik pada perokok meningkat 30 kali lipat dibandingkan dengan bukan perokok, ini berhubungan dengan paparan asapa rokok yang menyebabkan inflamasi kronis dan berakhir dengan perubahan dari epitel saluran napas tersebut. ${ }^{8}$ Penelitian Sajinadiasa dkk melaporkan resiko kanker paru 15 kali lebih besar pada pasien perokok dengan rasio prevalen 1,04 dan $\mathrm{p}=0,27 .{ }^{9} \quad$ Penelitian ini penyakit terbanyak yang berhubungan dengan perokok adalah karsinoma bronkogenik $38 \%$ diikuti dengan TB $28,6 \%$ dan pneumonia $16 \%$. Pasien perokok dengan karsinoma bronkogenik derajat merokoknya adalah derajat berat $43 \%$ dengan ketergantungan nikotin rendah sampai sedang56\% dan profil merokok pada pasien karsinoma bronkogenik adalah stress (80\%) sesuai dengan beberapa penelitian sebelumnya.

Penelitian Sujinadya dkk pasien PPOK terpapar rokok $81,3 \%$ dengan rasio prevalen 1,09 tidak bermakna secara statistik. Pada penelitian ini kejadian PPOK pada perokok lebih tinggi dari bukan perokok $(35,5 \%$ vs $7,8 \%)$, sedangkan pada bekas perokok didapatkan sekitar $11 \%$. Pasien perokok pada penelitian ini dengan diagnosa PPOK sebanyak sebanyak $8 \%$ dengan indeks brinkman berat $18 \%$, dan profil merokok terbanyak karena kesenangan $12 \%$ diikuti stress $17,6 \%$. Indeks brinkman berat berhubungan dengan lamanya pasien tersebut merokok, dan ketergantungan nikotinnya sedang $14 \%$, Berdasarkan fagerstorm indeks nikotin pada pasien PPOK pada level sedang karena ratarata pasien ini merokok dalam 30 menit 
setelah bangun pagi untuk merasakan kesenangan dan jumlah rokok yang di hisap dalam satu hari rata-rata lebih dari 20 batang.

Penelitian Dwi Sarwani dkk hasil analisis bivariat dengan uji chi kuadrat dan penghitungan OR, menunjukkan ada hubungan yang signifikan antara merokok dengan kejadian $\mathrm{Tb}$ paru. Orang yang merokok mempunyai risiko 3,8 kali lebih besar untuk menderita $\mathrm{Tb}$ paru di bandingkan yang tidak merokok. Hasil penelitian Ho Lin et all dan Gajalaksmi juga menyatakan merokok berhubungan dengan meningkatkan risiko tuberkulosis. ${ }^{0,11}$ Penelitian ini pasien $\mathrm{Tb}$ yang merokok berjumlah $18(\%)$ rata-rata pada umur \pm 44 tahun dengan indeks brinkman sedang $(60 \%)$ dan profil merokok terbanyak karena faktor sosial $(44,1 \%)$. Derajat ketergantungan nikotin berada pada level ringan (53\%). Pasien TB yang merokok kebanyakan karena faktor sosial dimana ikut-ikut merokok karena teman sekeliling merokok dan merasa populer karena merokok. Penelitian ini sejalan dengan penelitian Harvir dkk tahun 2010 melaporkan berdasarkan analisis multivariate regresi logistic merokok factor independen terjadinya TB paru (OR 3.05, $\mathrm{P}=0.000$ ), dan risiko TB pada perokok tergantung pada jumlah, durasi dan jenis rokok. $^{12,13}$

Merokok meningkatkan risiko infeksi pnemonia, ISPA dan juga Tb paru. Pasien dengan diagnosis pneumonia pada penelitian ini sebanyak $10(\%)$ pada jenis kelamin lakilaki dengan umur rata-rata \pm 54 tahun dan indeks brinkmannya Ringan (22\%). Laporan tentang bagaimana risiko rokok terhadap pneumonia belum kami dapatkan. Namun kematian akibat pneumonia berhubungan dengan rokok sebesar $26 \%$ pada laki-laki. Penelitian Sajinadiyasa melaporkan rasio prevalen pada pneumonia adalah 1,99, namun tidak bermakna secara statistik dengan $\mathrm{p}=0,28 .^{9}$ Pasien pneumonia yang merokok pada penelitian ini mempunyai profil merokok terbanyak karena stimulasi
$30 \%$ dimana mereka merokok agar mendapatkan pikiran yang tenang dan bisa berfikir dengan jernih. Derajat ketergantungan nikotin pada pasien ini derajat sedang 19\% mereka merokok terutama pada pagi saat bangun untuk mendapatkan pikiran yang jernih dan bisa berfikir dengan baik.

Pada penelitian ini pasien dengan diagnosa asma yang merokok cuma 1 orang dari 9 orang pasien asma yang dirawat pada periode penelitian ini. Prevalensi asma juga lebih banyak pada perempuan daripada lakilaki. Penelitian Sajinadiyasa juga melaporkan penderita asma yang terpapar rokok lebih rendah dari yang tidak terpapar rokok mungkin hal ini karena rokok bukan resiko kuat untuk terjadinya asma dan untuk memastikan kemungkinan ini diperlukan penelitian lebih lanjut. Pasien asma yang merokok ini mempunyai indeks brinkman berat dengan umur 45 tahun, dan profil merokok kesenangan dengan derajat ketergantungan nikotin sedang.

Pasien bronkiektasi pada penelitian ini tidak ada yang merokok satu pun, karena pasien yang didiagnosis bronkiektasis semuanya wanita. Rokok merupakan salah satu factor risiko bronkiektasis karena rokok menyebabkan terjadinya inflamasi kronis pada saluran nafas yang akan berakibat pada kerusakan dinding-dinding saluran nafas mulai dari bronkus sampai alveolus. Kerusakan ini salah satunya bisa menyababkan terjadinya dilatasi pada saluran nafas bagian distal bronkus terminalis.

\section{KESIMPULAN}

Pasien yang dirawat di bangsal paru lebih dari sepertiga adalah perokok. Profil yang paling umum adalah untuk kesenangan dan ketergantungan nikotin sebagian besar rendah hingga sedang, sehingga dapat memberikan kesempatan bagi kita untuk melakukan program berhenti merokok.

\section{DAFTAR PUSTAKA}

1. Mc.Ewen, Hajek P, Mc.Robbie, West R. Manual of Smoking Cessation a Guide 
for Councellors and Practitioners. 1st ed. Oxford: Blackwell publishing; 2007.

2. WHO. WHO Report on the Global Tobacco Epidemis. The MPOWER Package. 1st ed. (WHO, ed.). Jeneva: WHO; 2008.

3. Mackay J, Michael E. Tobacco Atlas. 2nd ed. Jeneva: WHO; 2002.

4. WHO. "Tobacco" Fact Sheet No 339. Geneva; 2015.

5. Departemen K. Survei Kesehatan Rumah Tangga 2001. (Departemen K, ed.). Jakarata: Departemen Kesehatan; 2008.

6. Badan Penelitian dan Pengembangan Kesehatan-Kementerian Kesehatan RI. Riset Kesehatan Dasar 2010. (Kesehatan-Kementerian BP dan P, ed.). Jakarta: Kementrian Kesehatan RI; 2011.

7. Samet JM. Commentary Epidemiology and the Tobacco Epidemic: How Research on Tobacco and Health Shaped Epidemiology. Americcan J Epidemiol. 2016;183(5):394-402. doi:10.1093/aje/kwv156

8. Walser T, Cui X, Yanagawa J, et al. Smoking and lung cancer: The role of inflammation. Proc Am Thorac Soc. 2008;5(8):811-815.

doi:10.1513/pats.200809-100TH

9. Sajinadiyasa I, Bagiada I, Ngurah Rai I. Prevalensi Dan Risiko Merokok Terhadap Penyakit Paru Di Poliklinik
Paru Rumah Sakit Umum Pusat Sanglah Denpasar. J Intern Med. 2010;11(2):9195.

10. Gajalakshmi V, Peto R, Kanaka TS, Jha P. Smoking and mortality from tuberculosis and other diseases in India: Retrospective study of 43000 adult male deaths and 35000 controls. Lancet. 2003;362(9383):507-515. doi:10.1016/S0140-6736(03)14109-8

11. Lin HH, Ezzati M, Chang HY, Murray M. Association between tobacco smoking and active tuberculosis in Taiwan: Prospective cohort study. Am J Respir Crit Care Med. 2009;180(5):475480. doi:10.1164/rccm.200904-0549OC

12. Gambhir HS, Kaushik RM, Kaushik R, Sindhwani G. Tobacco smokingassociated risk for tuberculosis : a casecontrol study. Int Health. 2010;2(3):216222. doi:10.1016/j.inhe.2010.07.001

13. Den Boon S, Van Lill SWP, Borgdorff MW, et al. Association between smoking and tuberculosis infection: A population survey in a high tuberculosis incidence area. Thorax. 2005;60(7):555-557. doi:10.1136/thx.2004.030924 